\title{
Prohibitin and RACK homologues are up-regulated in trypanosomes induced to undergo apoptosis and in naturally occurring terminally differentiated forms
}

\author{
Susan C. Welburn", and Noel B. Murphy ${ }^{2}$ \\ ${ }^{1}$ corresponding author: S Welburn, Tsetse Research Group, Division of \\ Molecular Genetics, Institute of Biomedical and Life Sciences, University of \\ Glasgow, 56 Dumbarton Road, Glasgow G11 6NU, UK. tel: (44) 141-339- \\ 8855, fax: (44) 141-330-4877, email: sue.welburn@tsetse.demon.co.uk \\ 2 International Livestock Research Institute, P.O. Box 30709, Nairobi, Kenya
}

Received 8.1.98; revised 5.2.98; accepted 11.3.98

Edited by R.A. Knight

\begin{abstract}
Two genes have been identified as up-regulated late during ConA-induced apoptosis in procyclic form Trypanosoma brucei rhodesiense. The first represents a homologue of prohibitin, a proto-oncogene originally described in mammals and subsequently in yeast, which is involved in cell-cycle control and senescence. The Trypanosoma prohibitin homologue appears to contain within it a putative death domain. The second gene, homologous to a family of regulatory proteins which are receptors for activated protein kinase C (RACKs), is also shown to be up-regulated in terminally differentiated bloodstream form trypanosomes. These are the first endogenous genes to be identified as upregulated in programmed cell death (PCD) in unicellular organisms.
\end{abstract}

Keywords: apoptosis; prohibitin; RACK; Trypanosoma brucei rhodesiense; programmed cell death; lectin; differential display; differential gene expression

Abbreviations: bp, base pair(s); ConA, concanavalin A; FBS, foetal bovine serum; EtdBr, ethidium bromide; kbp, kilobase pair(s); PCD, programmed cell death; RADES-PCR, randomly amplified differentially expressed sequences - polymerase chain reaction; RACK, receptor for activated protein kinase C; TRACK, trypanosome receptor for activated protein kinase $\mathrm{C}$

\section{Introduction}

Programmed cell death (PCD) and apoptosis were assumed until recently to have evolved to regulate growth and development in multicellular organisms. A regularised system of cell death, among other essential developmental programmes, was thought to have appeared in phylogenesis after the onset of multicellularity. The demonstration of apoptosis in a number of unicellular organisms, including several parasites, has implications for our understanding of the origins of PCD in eukaryotic cell survival and may offer new possibilities for controlling parasitic disease (Ameisen, 1996; Welburn et al, 1997). Evidence for PCD and/or apoptosis has been presented for Dictostellium (Cornillon et al., 1994) and in three members of the parasitic trypanosomatids: Trypanosoma cruzi (Ameisen et al, 1995), T. brucei rhodesiense (Welburn et al, 1996) and Leishmania L. amazonenis (Moiera et al, 1996). These studies have however been limited to describing morphological features of cell death which resemble the characteristics of apoptosis in metazoa, the most common form of PCD in multicellular organisms (Ameisen, 1996). More recently work in yeast examining the role of defined mammalian apoptotic proteins such as Bax (which drives a mammalian cell towards death) and $\mathrm{Bcl}$ (which counteracts this process) has shown that these proteins function in a similar manner in yeast although yeast do not appear to contain homologues of these genes (Ink et al, 1997; Tao et al, 1997). The identification of genes that regulate cell suicide in unicellular organisms is essential in order to address many of the issues concerning the social control of cell survival and to establish whether unicellular eukaryotes share the same or similar regulators of cell suicide programmes with multicellular organisms. Trypanosomes are of particular interest in this regard as they represent the most primitive eukaryote in which PCD has been described. Previous work has shown that trypanosomes actively participate in their own destruction through a PCD process and confirmed that cell death in trypanosomes is associated with de novo gene expression (Murphy and Welburn, 1997). The present work describes the isolation and cloning of the full gene sequence from RADES products up-regulated during cell death and considers the role of these proteins in unicellular cell death.

\section{Results}

\section{Examination of differential gene expression in ConA treated parasites}

To identify genes which may be up-regulated during cell death in $T$. b. rhodesiense we have treated the parasites with ConA and used a differential display method called RADES-PCR [randomly amplified differentially expressed sequences PCR (RADES-PCR)], (Murphy and Pelle, 1994) for the identification of genes up-regulated late in the death process. RADES-PCR has been shown to be a highly sensitive method for the examination of gene expression in dying trypanosomes (Murphy and Welburn, 1997). Previous work indicated that ConA induced cell death in $T$. $b$. rhodesiense was reversible up to $7 \mathrm{~h}$ post treatment but thereafter cells were irreversibly committed to dying (Murphy and Welburn, loc. cit.). When single primer (1501) RADES-PCR reactions were carried out on cDNA templates prepared from 
trypanosomes treated for varying lengths of time with ConA, small alterations were evident in the RADES - PCR products from parasites harvested at different time intervals which were reproducible at lower template concentrations. In the $48 \mathrm{~h}$ template two products of approximately 150 and $200 \mathrm{bp}$ appeared which were absent in untreated cells and cells treated with ConA for shorter periods. The observed upregulation of two transcripts late during the death process at $48 \mathrm{~h}$ would suggest that the parasites are undergoing a form of regulated cell death.

\section{mRNAs up-regulated $48 \mathrm{~h}$ into cellular death correspond to two genes from the prohibitin and RACK gene families}

The two RADES products displaying altered amplification in ConA treated parasites in the $48 \mathrm{~h}$ template gel were excised and re-amplified with primer 1501, gel purified and cloned into pGEM-T (Promega) and sequenced. Following a search of the DNA sequence databases they were found to be homologous to sequences present in two gene families: the prohibitin/ Bap37 gene family and the RACKs (a family of receptors for activated protein kinase $\mathrm{C}$ ). The $200 \mathrm{bp}$ RADES product showed initial identity of $39 \%$ with the Caenorahabditis elegans prohibitin homologue in over 64 amino acids and the 150 bp RADES product showed $64 \%$ initial identity over 45 amino acids with the RACK sequence from Leishmania major (LACK). These DNAs were used as probes to screen lambda gt11 genomic and cDNA libraries of $T$. b. brucei prepared from actively dividing bloodstream form trypanosomes.

\section{A gene up-regulated in dying parasites is identified as a new member of the prohibitin gene family}

A genomic clone containing the full open reading frame for prohibitin was isolated from the lambda gt11 library. The genomic clone contained an open reading frame of 265 amino acids and confirmed the parasite gene as a new member of the prohibitin/Bap 37 gene family. The predicted amino acid sequence for this gene indicates a protein Mwt $27 \mathrm{kDa}$, pl 9.0. Alignment of the predicted amino acid sequence of trypanosome prohibitin with other members of the prohibitin gene family (Figure $1 \mathrm{~A}$ ) showed $46 \%$ identity with the human prohibitin (accession S85655); 45\% identity with yeast prohibitin (accession Z72917) and 42\% identity with mouse BAP37 [a related member of the prohibitin gene family (accession S46996)]. The predicted amino acid sequence for the trypanosome protein also showed $44 \%$ identity with prohibitin from Coenorhabditis elegans (accession U28940) and $38.2 \%$ identity with Drosophila Cc (accession P24156) alignments not shown. Southern blot hybridization revealed prohibitin to be present as a single copy gene in $T$. $b$. rhodesiense and despite low stringency hybridization the putative trypanosome homologue for BAP37 (accession AA701846) [a gene highly homologous to prohibitins in the mid region found in mammals and yeast (Coates et al, 1997)] was not detected (data not shown). Comparison at the DNA level between trypanosome prohibitin and the incomplete sequence available for BAP37 shows $50 \%$ homology mainly in the mid region of the genes.
Trypanosome prohibitin contains a putative death domain with homology to the prostate apoptosis response gene par-4

The prohibitin trypanosome homologue appears to contain a region of leucine repeats within its reading frame. Alignment of the predicted amino acid sequence of this helical region of Trypanosoma prohibitin with the predicted death domains of other proteins critically involved in the induction of apoptosis (Figure 1B) shows a significant degree of homology especially to the prostate apoptosis response gene, par-4 (Diaz-Meco et al, 1996). The death domains of trypanosome prohibitin, par4, Drosophila reaper, and mouse RIP all show similarity to human Fas in which the death domain is comprised of six amphipathic alpha helices arranged antiparallel to one another (Huang et al, 1996). Prohibitin presents 16.5\% similarity to the predicted death domain of par- $4 ; 14.3 \%$ similarity to human Fas; $12.7 \%$ similarity to Reaper and $10.4 \%$ to mouse RIP (using PAM250 residue weight tables).

\section{Prohibitin is up-regulated in dying parasites, as confirmed by Northern blot analysis, with maximum expression at $24 \mathrm{~h}$}

To confirm that prohibitin was up-regulated during death of parasites, RNA was prepared from ConA treated parasites at $0,4,8,24,48 \mathrm{~h}$ and a Northern blot prepared from dying parasites using the full gene sequence of prohibitin as a probe. The Northern blot was exposed for 14 days as the abundance of prohibitin transcripts is relatively low. The abundance of transcripts increased steadily during ConA induced apoptosis in these parasites with maximum expression at $24 \mathrm{~h}$. Transcript abundance at $24 \mathrm{~h}$ was $4-5$-fold higher than at the zero time-point confirming the differential display results that this gene is up-regulated during cell death (Figure 2). Although the relative abundance of prohibitin transcripts were low, the RADES-PCR differential display method was sufficiently sensitive to detect altered expression of this low abundance transcript during ConA-induced PCD. Hybridisation of a Northern blot of this RNA with $\beta$-tubulin confirmed RNA fidelity showing equal intensity labelling of message for this housekeeping gene over the $48 \mathrm{~h}$ period (data not shown).

\section{A gene up-regulated in dying parasites is identified as a new member of the RACK gene family}

The RADES DNA product for the trypanosome RACK homologue was similarly radiolabelled and used to screen the lambda gt11 genomic and cDNA libraries for the full length sequence. After library screening two full length cDNAs (1kB) were obtained for the trypanosome RACK homologue predicting a protein open reading frame of 319 amino acids. The predicted amino acid sequence for this gene indicates a protein mwt $34 \mathrm{kDa}$ which showed strong homology with intracellular receptors for activated protein kinase $\mathrm{C}$, or RACKs, and was designated TRACK. RACKs are members of an ancient family of regulatory proteins containing four to eight copies of a conserved motif that usually ends with a tryptophan-aspartate (WD) dipeptide. The TRACK gene 
a

Human

Yeast

Mouse Bap37

Trypanosome

Human

Yeast

Mouse Bap37

Trypanosome

Human

Yeast

Mouse Bap37

Trypanosome

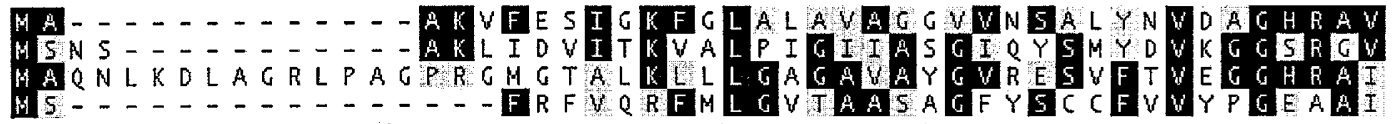

Human

Yeast

Mouse Bap37

Trypanosome

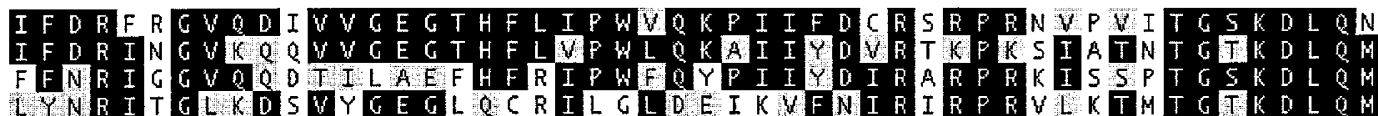

Human

Yeast

Mouse Bap37

Trypanosome

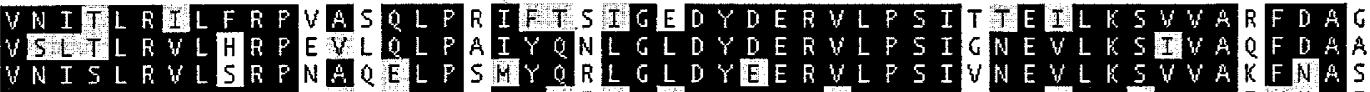

Human

Yeast

Mouse Bap37

Trypanosome

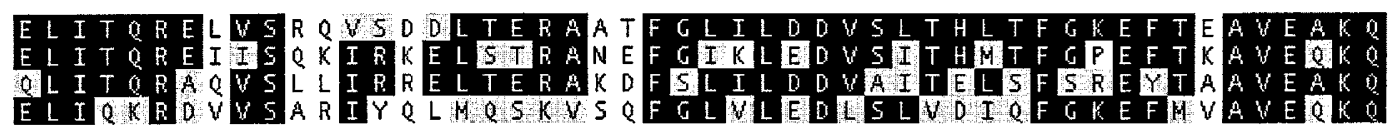

b
Human FAS
I A G VMTLSQVKGFVRKNGVNE
A K I D E I K N D N V Q D T A E Q K V
Human RIP
IR ENLG-KHWKNCARIKLGFTE
Reaper
Par 4
R E A E Q K E Q Q I L R L RE S Q W
Prohibitin
A N V S GTL - - VSSSTLEKKIEDLEKEVVRER-QENL- R R - - - RILPSISNEILKAVVAEYKAEELIRK- - RDVYSARI
Human FAS
Human RIP

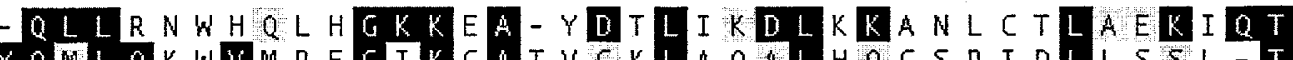
Reaper
Par-4
Prohibitin

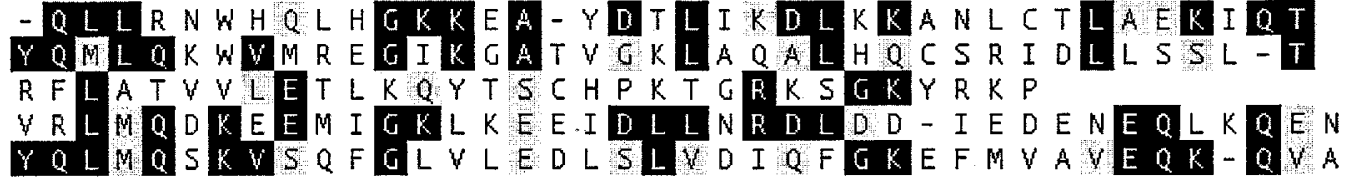

Figure 1 (A) Alignment of the predicted amino acid sequence of trypanosome prohibitin (accession AF049901) with other members of the prohibitin gene family: human prohibitin (accession S85655); yeast prohibitin (accession Z72917) and with mouse BAP37 [a related member of the prohibitin gene family (accession S46996)]. Black boxes indicate complete amino acid sequence identity; grey shading similarity at three distance units through conservative amino-acid substitutions. (B) Amino-acid sequence alignment of $T$. $b$. rhodesiense prohibitin coiled coil region and the death domain containing proteins human Fas, human RIP, Drosophila reaper and human Par-4. Black boxes indicate complete amino acid sequence identity; grey shading similarity at three distance units through conservative amino-acid substitutions. The Fas death domain consists or six amphipathic alpha helices arranged antiparallel to one another and death domains found in other proteins such as TNF-R1, FADD, TRADD and RIP are homologous to Fas in this region (Huang et al, 1995)

contains four regularly spaced WD amino acid sequence motifs.

Percentage identity between TRACK and LACK, the corresponding gene from the distantly related Leishmania spp (Mougneau et al, 1995) was 57\% (Leishmania chagasi) suggesting that this protein is highly conserved within the trypanosomatids (Figure 3). TRACK is phylogenetically more closely related to the RACKs from man and yeast than is the corresponding protein from Leishmania spp. TRACK shows $53.3 \%$ similarity to human RACK and $42.4 \%$ to yeast RACK while the LACK gene from Leishmania presents less homology to these proteins with only $42.4 \%$ similarity to the human RACK and $32.7 \%$ to the gene from yeast. Both the LACKs and TRACK have conserved cysteine residues at amino acids 21 and 121 and share a conserved region between amino acid 49-52 unique to the trypanosomatid proteins. The TRACK amino acid sequence shows a region of closer homology to the RACKs rather than to LACK between amino acids 69-73.

\section{TRACK is up-regulated in dying insect form parasites with maximum expression at $48 \mathrm{~h}$ after treatment with ConA and also in terminally differentiated bloodstream forms}

To confirm that TRACK was up-regulated in dying parasites TRACK CDNA was labelled and used to hybridise to RNA prepared from procyclic parasites induced to undergo PCD following treatment with ConA. In contrast to prohibitin, the abundance of TRACK transcripts is relatively high and consequently hybridizing transcripts were easily detected after an overnight exposure of the Northern blot. The TRACK 


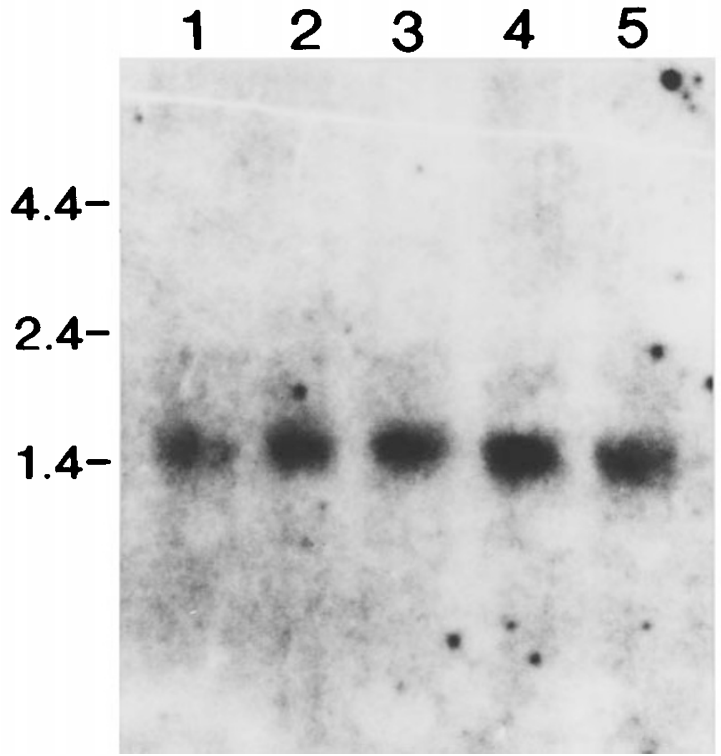

Figure 2 RNA isolated from $T$. $b$. rhodesiense parasites undergoing apoptosis 0 (control), 4, 8, 24 and $48 \mathrm{~h}$ following treatment with the lectin ConA lanes 1-5 respectively. Position of molecular size markers (BRL) 4.4 2.4 and $1.4 \mathrm{~kb}$ marked to left
cDNA hybridized to a single $T . b$. rhodesiense transcript at $1.2 \mathrm{kB}$. Increasing hybridization of this CDNA was observed at 24 and $48 \mathrm{~h}$ into the death process as the insect form parasites underwent lectin-induced death (Figure 4A). TRACK was also hybridized to RNA prepared from two stages of the mammalian bloodstream form parasite: shortstumpy terminally-differentiated forms and long-slender actively-dividing forms (Vickerman, 1985). Although a $1200 \mathrm{nt}$ transcript was present in both short-stumpy and long-slender form trypanosomes, TRACK was significantly up-regulated in the short stumpy (terminally differentiated) parasites (Figure 4B). Hybridization of a Northern blot of this RNA with $\beta$-tubulin confirmed RNA fidelity showing equal intensity labelling of message for this housekeeping gene over the $48 \mathrm{~h}$ period (data not shown).

\section{Discussion}

Genes implicated in apoptosis in single-celled organisms are of great interest for our understanding of the evolutionary significance of apoptosis and programmed cell death. Although several mammalian effectors of cell death have been shown to be functionally active in yeast [including Bax which accelerates the apoptotic process and members of the

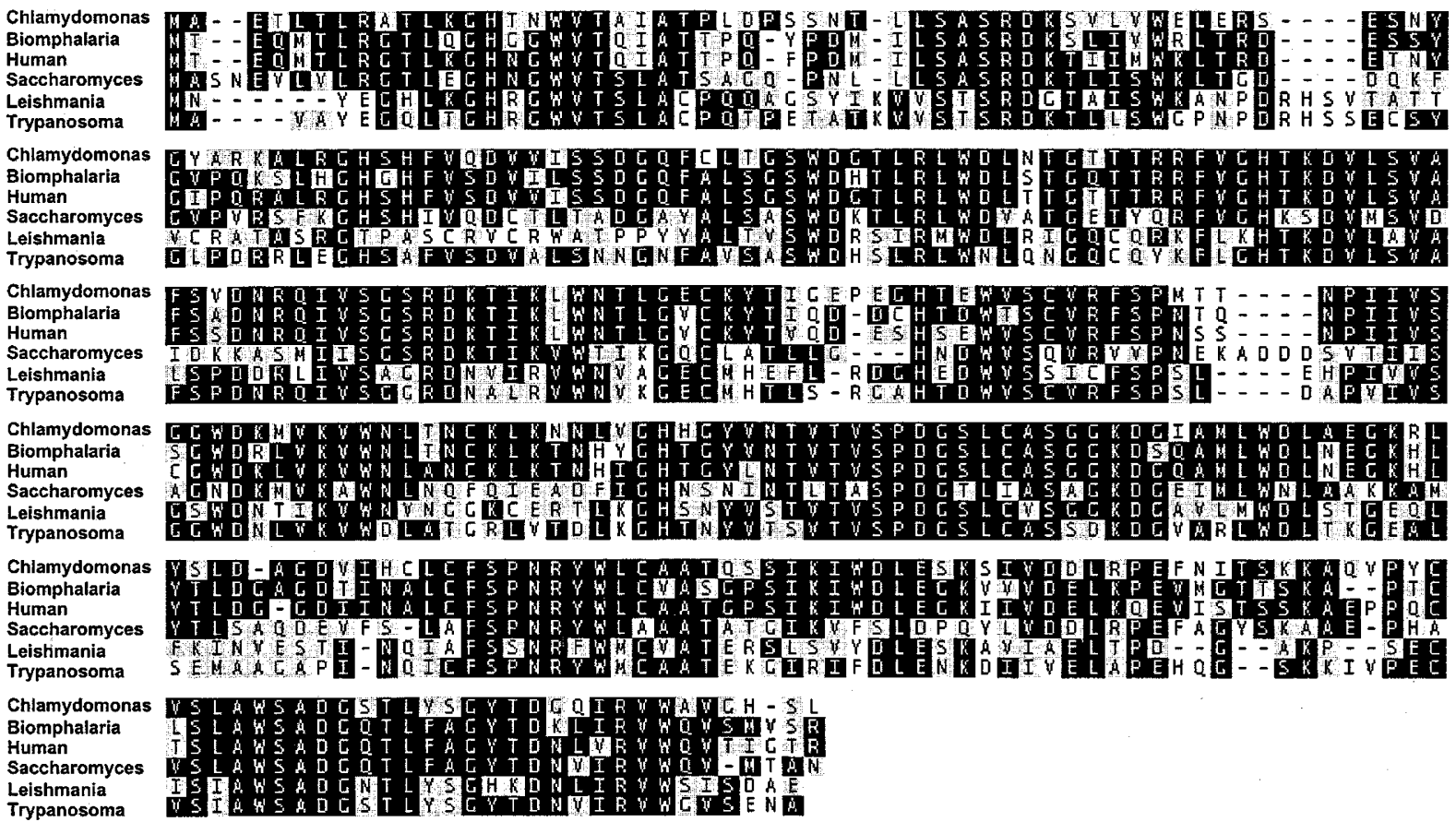

Figure 3 Alignment of the predicted amino acid sequence for $T$. b. rhodesiense TRACK (accession AF049902) with other RACKs from Chlamydomonas reinhardtii (accession X53574); Biomphalaria glabrata (accession U49437); human RACK (accession A33928); Saccharomyces cerevisiae (accession Z49702); Leishmania chagasi (accession U27569). TRACK presents an open reading frame of 319 amino acids containing four regularly spaced WD amino acid sequence motifs. Black boxes indicate complete amino acid sequence identity; grey shading similarity at three distance units through conservative amino-acid substitutions. Percentage identity between TRACK and LACK, the corresponding gene from Leishmania spp (Mougneau et al, 1995) was 57\% (Leishmania chagasi) suggesting that this protein is highly conserved within the trypanosomatids. TRACK shows $53.3 \%$ similarity to human RACK and $42.4 \%$ to yeast RACK while the LACK gene from Leishmania presents less homology to these proteins with only $42.4 \%$ similarity to the human RACK and $32.7 \%$ to the gene from yeast. Both LACKs and TRACK have conserved cysteine residues at amino acids 21 and 121 and share a conserved region between amino acid $49-52$ unique to the trypanosomatid proteins. The TRACK amino acid sequence shows a region of closer homology to the RACKs rather than to LACK between amino acids $69-73$ 
a

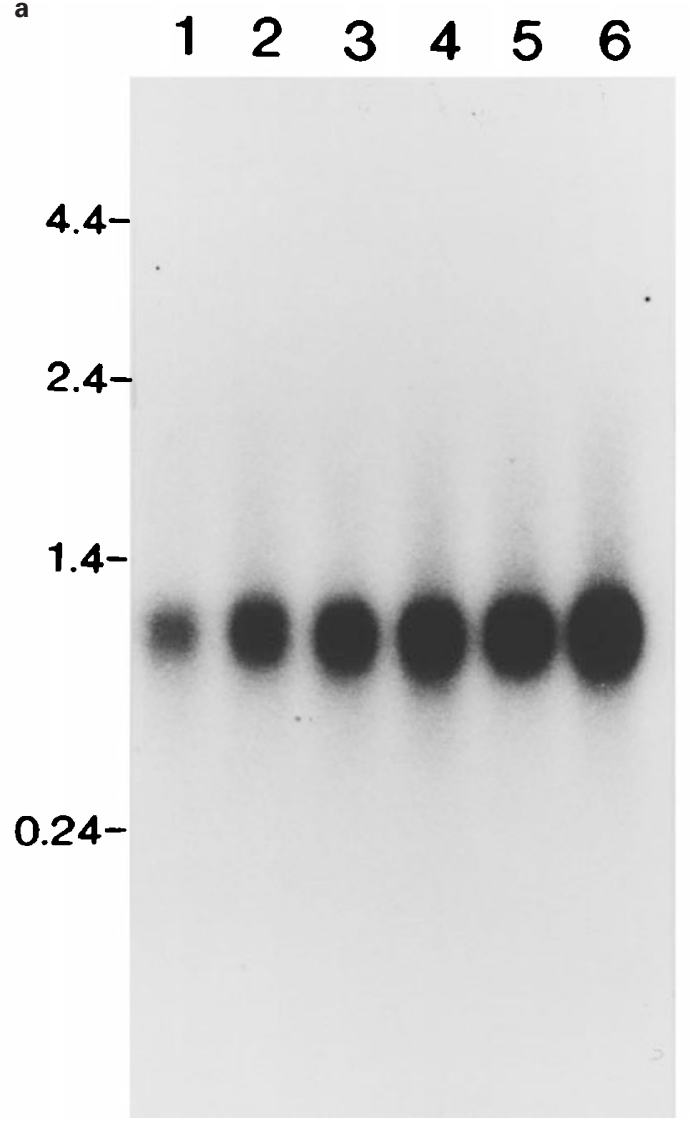

b

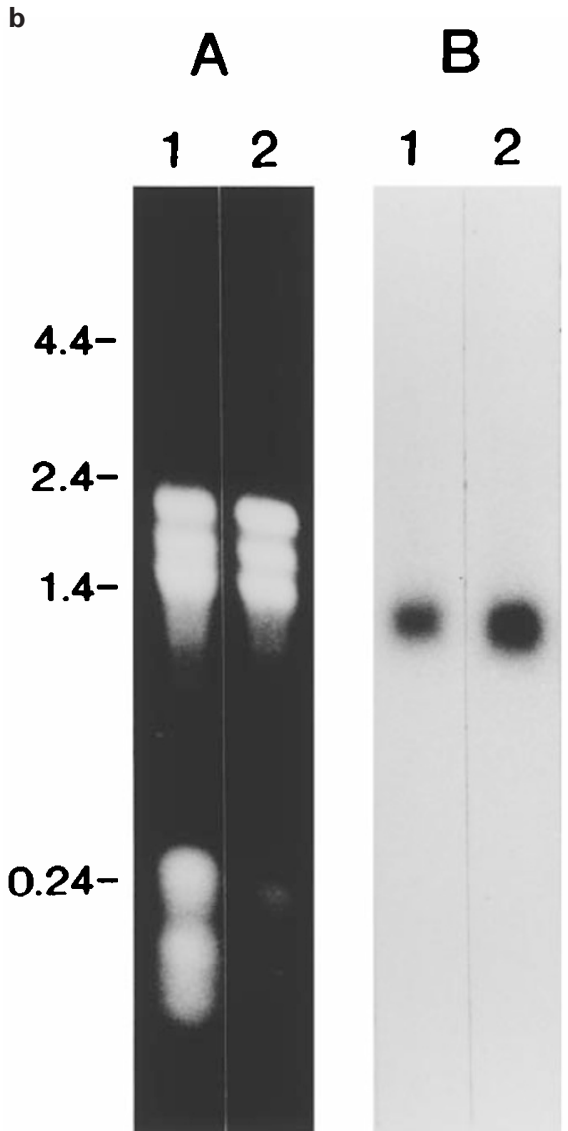

Figure 4 (A) Hybridization of TRACK to RNA from untreated control procyclic $T$. b. rhodesiense (lane 1) and parasites treated with ConA and harvested at 2, 4, 7, 24 and $48 \mathrm{~h}$ (lanes 2-6 respectively). Position of molecular weight size markers (BRL) 4.4, 2.4, 1.4 and $0.24 \mathrm{~kb}$ marked to left. TRACK cDNA hybridized to a single T. b. rhodesiense transcript at $1.2 \mathrm{kB}$. Increasing hybridization of this cDNA was observed after ConA treatment with maximum expression $48 \mathrm{~h}$ into death. (B) TRACK cDNA was also used to hybridize to RNA prepared from two forms of mammalian bloodstream form parasites: short stumpy terminally differentiated forms and long slender actively dividing forms. Lanes A represent fidelity of RNA isolated from $T$. $b$. brucei bloodstream form long slender actively dividing (lane A1) and short stumpy terminally differentiated forms (lane A2). [Note the three distinct $T$. brucei s.l. ribosomal RNA bands (approximately $2.2,1.7$ and $1.5 \mathrm{~kb}$ ) and smaller RNA transcripts, including tRNA molecules, are clearly visible in both life cycle forms]. RNA was hybridized to TRACK cDNA and while transcripts were present in both long slender form trypanosomes (lane B1) and short stumpy parasites (lane B2) at 1200 nucleotides, TRACK was significantly up-regulated only in the short stumpy (terminally differentiated) parasites. Position of molecular weight size markers (BRL) $4.4,2.4,1.4$ and $0.24 \mathrm{~kb}$ marked to left

Bcl-2 family which suppress programmed cell death (Ink et al, 1997; Tao et al., 1997)], no natural yeast homologues of such regulatory proteins have been described in single-celled organisms suggesting that unicellular organisms have alternative control mechanisms for cell death and multiplication which evolved prior to the onset of multicellularity. We have previously shown that trypanosomes can be induced to undergo apoptosis after stimulation with ConA and in the present study we have used a differential display method, RADES-PCR (Murphy and Pelle, 1994), to examine gene expression in dying parasites (Welburn et al, 1996; Murphy and Welburn, 1997). Using this approach we have identified two genes, prohibitin and TRACK, which are up-regulated during cell death and which have homologues in multicellular organisms.

Prohibitins are a family of highly conserved nuclear encoded mitochondrial proteins identified in mammals (Terashima et al., 1994), Drosophila (Eveleth and Marsh, 1986), C. elegans (Terashima et al., loc. cit.), plants (Snedden and Fromm, 1997) and yeast (Jazwinski, 1996) whose cellular roles still remain unclear but which have been implicated in cell-cycle regulation and tumour suppression in mammals and in determining yeast replicative lifespan. The amino acid sequences of mammalian prohibitins are highly conserved with rat differing from the human protein sequence by only a single amino acid. Despite this conservation and various proposed roles in cellular processes, a universal role for members of the prohibitin gene family in higher organisms has not been described. Prohibitin has not been associated with cell death in multicellular organisms although $\mathrm{Cc}$, the prohibitin homologue in Drosophila, is vital for normal development as mutants in this gene fail to develop past the embryonic stage (Nuell et al, 1991). The first prohibitin described was isolated as a cDNA expressed at higher levels in non-proliferating compared to regenerating rat liver. Mutations found in this gene in the presence of some tumours were suggestive of tumour supressor activity (Sato et al, 1992). The $30 \mathrm{kD}$ protein is located in the mitochondrial inner membrane where it is postsynthetically 
modified; tag positioning at the amino-terminus (which shares characteristics of known mitochondrial import signals) causes cytoplasmic accumulation of prohibitin, again suggestive of tumour suppressor activity (Ikonen et al, 1995). The expression pattern of the prohibitin gene in rat testes also appears to correlate with a proposed antiproliferative role of probibitin as the protein was not detected in spermatogonia and spermatocytes undergoing mitotic and meiotic divisions whereas it was found to be constitutively expressed in adult Leydig and Sertoli cells at all stages (Choongkittaworn et al, 1993).

A yeast homologue of prohibitin has been identified in Saccharomyces cerevisieae which is preferentially expressed in young yeast cells with expression decreasing as the cells age. Deletion of prohibitin in haploid yeast cells is non-lethal and can extend the yeast life-span by approximately 30\%; over-expression of prohibitin decreased the mean life-span by $20 \%$ (Franklin and Jazwinski, 1993). In human fibroblasts expression of prohibitin mRNA and protein changes little with increasing age in vitro, although the protein product is postsynthetically modified in younger but not older cells analogous to the retinoblastoma gene product (Liu et al, 1994).

In mammals and yeast prohibitin co-exists with a homologous protein BAP37, the mid regions of which are remarkably similar containing a series of repeated leucine residues and a predicted coiled coil region; both proteins are presumed to have been present during evolution for approximately 2 billion years (Coates et al, 1997). In both mammals (Terashima et al, 1994) and yeast (Coates et al, loc. cit.) prohibitin and BAP37 are co-expressed, are present in mitochondria and interact with each other. Trypanosomes possess a single copy of the prohibitin gene and also appear to have a BAP37 homologue (recently identified by random cDNA sequencing); it is not clear what the precise nature of the interaction between prohibitin and the similar BAP37 proteins in mammals, yeast and trypanosomes might be which necessitates the two similar proteins. Deletion of either gene in yeast exerted only an intermediate effect on mean and maximum replicative lifespan which was most significant in cells lacking both genes; the double knockouts did however present a reduction in mitochondrial membrane potential by 80\% (Coates et al, 1997). Expression of both prohibitin and BAP37 is low in normal cells when compared to immortal cell lines and tumours (Terashima et al, 1994; Asamoto and Cohen, 1994). Similarly in T. b. rhodesiense it is clear that expression of prohibitin is relatively low in normal activelydividing cells and expression is only enhanced when the cells are dying with maximum expression at $24 \mathrm{~h}$ after stimulation with ConA. In yeast, the prohibitin gene is reported to lie on a genetic pathway upstream of RAS2 which controls the response to ultraviolet irradiation and other stresses, and prohibitin may decrease activity of the Ras2p protein (Jazwinski, 1996).

The ability to negatively regulate cell proliferation is necessary for all living organisms and unicellular organisms must limit their replication to the times when adequate nutrients and other environmental factors are present. The fact that prohibitin and a similar intracellular protein BAP37 are found non-covalently associated with $\lg M$ and not $\lg G$ receptors on murine $B$ lymphocytes (Terashima et al, 1994) may suggest how signalling through the IgM receptor can result in inhibition of cell replication, or apoptosis, while binding of $\operatorname{lgG}$ receptors is stimulatory to the cell.

The homology in the leucine repeat coiled-coil region of $T$. b. rhodesiense prohibitin with the $C$ terminal part of the deduced amino acid sequence of par-4, the prostate apoptosis response gene, and the homology of both of these proteins in this region to known death domain containing proteins may be significant. Par-4 was isolated from an androgen-independent prostate cancer cell line and is specifically induced during apoptosis. Expression of this gene has been shown to correlate with growth inhibition and apoptosis (Sells et al, 1994). The deduced amino acid sequence of par-4 predicts a coiled coil-leucine zipper at the C-terminal part of the protein which is required for the protein to function in apoptosis (Sells et al, 1997). Death domains appear to modulate multimeric interactions between receptor-associated proteins that can induce apoptosis and the gene product of par- 4 has been shown to interact with the regulatory domains of the atypical subgroup of protein kinase $C$ (PKCs) through binding to the zinc finger region of these kinases, suggesting that inhibition of atypical PKCs may trigger cell death. It is in this mid leucine repeat coiled-coil region of the prohibitin gene that most homology is conserved among the prohibitins and with the related BAP37 genes.

TRACK, the second gene isolated as up-regulated during ConA-induced death of trypanosomes, is a receptor for activated protein kinase $\mathrm{C}$ which is expressed in actively dividing procyclic (insect form) and bloodstream form (mammalian infective) parasites. The relative amounts of RNA are seen to increase significantly during cellular death of procyclic form parasites with maximal expression at $48 \mathrm{~h}$ after ConA treatment. Interestingly, expression of TRACK is also increased in bloodstream form parasites which have become terminally differentiated in the mammal. These 'stumpy form' parasites have stopped dividing in the mammalian bloodstream and can only survive if ingested by the tsetse fly vector in which case they differentiate to procyclic forms at the lower temperature $\left(25^{\circ} \mathrm{C}\right)$ of the insect gut (Vickerman, 1985). It is possible, in the light of the results presented here, that these mammalian terminally differentiated forms are undergoing apoptosis in the mammalian bloodstream; they could then be cleanly removed from the population without promoting massive parasite lysis and subsequent inappropriate immune responses which could be detrimental to the remaining long slender parasite population as well as to the host.

In Leishmania major and L. chagasi a single gene has been identified for LACK which has two RNA transcripts of 1800 and $1500 \mathrm{nt}$. The LACK gene corresponds to a $36 \mathrm{kD}$ protein highly conserved in Leishmania sp. which is expressed in promastigotes and amastigotes. Immunization of susceptible mice with LACK and IL12 was shown to protect against infection with Leishmania major. LACK is thought to target $\mathrm{CD}^{+}$cells resulting in a Th1 response and production of IFN- $\gamma$ (Mougneau et al, 1995). 
RACKs are members of an ancient family of regulatory proteins containing four to eight copies of a conserved motif that usually ends with a tryptophan-aspartate (WD) dipeptide (Mochly-Rosen et al, 1995). The function of the WD repeat motif remains undefined but WD repeats often exist in multiprotein complexes suggesting a general regulatory role in either facilitating macromolecular assembly or in controlling protein-protein interactions. The upregulation of a receptor for activated protein kinase $C$ is suggestive of a role for protein kinase $C$ in cell death in trypanosomes. In higher eukaryotes protein kinase $C$ has been found to play a central role in PCD (Lavin et al, 1996) suggestive of similarities in the PCD process between primitive trypanosomes and multicellular organisms.

From these initial data it appears that there is a high level of conservation between the genes involved in cell death in trypanosomes and their mammalian homologues, although neither gene described here has been previously implicated in PCD in mammals. At present it is clear that several mammalian genes which affect apoptosis in mammalian systems also function in yeast but whether these single-celled organisms posses endogenous homologues for the mammalian genes for apoptosis is unclear. The present work has shown that $T . b$. rhodesiense possess at least two genes which have conserved homologues in mammals, Drosophila, C. elegans and yeast and, at least in trypanosomes, these genes are upregulated during induction of apoptosis in vitro and during terminal differentiation in vivo.

\section{Materials and Methods}

\section{Trypanosomes}

Procyclic forms: $T$. b. rhodesiense (stock OBWANG isolated from a patient during a sleeping sickness epidemic in S. E. Uganda, 1990) were transformed to procyclic form by transmission through tsetse flies. Trypanosomes were dissected from tsetse guts and cultured at $27^{\circ} \mathrm{C}$ in Cunningham's medium (CM) supplemented with $20 \%$ FBS (Welburn et al, 1996).

Bloodstream forms: long-slender and short-stumpy bloodstream forms of $T$. $b$. brucei (ILTat 1.1) were isolated from the blood of a rat as previously described (Murphy and Pelle, 1994).

\section{Induction of apoptosis}

The different procyclic $T$. $b$. rhodesiense cDNA templates were generated by treatment of log phase trypanosomes $\left(10^{6} / \mathrm{ml}\right)$ with $1 \mu \mathrm{g} /$ $\mathrm{ml}$ ConA type IV (Sigma, UK) in procyclic culture media (CM supplemented with 17\% FBS) as previously described (Welburn et al, 1996).

\section{Preparation of RADES template}

Total RNA was prepared from parasites at each time point $(0,2,4,7$, 24 and $48 \mathrm{~h}$ ) and analyzed by electrophoresis (Pelle and Murphy, 1993). RNA was enriched for poly(A) and conversion to cDNA was effected using Moloney murine leukemia virus (M-MLV) reverse transcriptase and an oligo (dT) primer (ILO1487 - TAG GCG CGC CTT TTT TTT TTT TTT TTT TTT). After removal of the oligo
$d(T)$ primer and dNTPs via a Centricon 30 column (Amicon), ds cDNA was generated using specific primers for the conserved $25 \mathrm{nt}$ at the $3^{\prime}$ end of the miniexon spliced leader of trypanosome mRNA (ILO1488 TAG GCG CGC CTA GAA CAG TTT CTG TAC TAT ATT G) containing nt 16 to 39 of the miniexon sequence. PCRs contained $100 \mathrm{ng}$ cDNA/10 $\mu \mathrm{l} 10 \times$ Taq buffer [10 mM Tris-HCL (pH 8.3)]/2 mM MgCl $2 /$ $4 \mu \mathrm{l} 5 \mathrm{mM}$ dNTPs/2.5 u Taq DNA polymerase $/ 1 \mu \mathrm{l}(100 \mathrm{ng} / \mu \mathrm{l})$ each of the oligo(dT) primer (ILO1487) and miniexon primer (ILO1488) in $100 \mu$ total volume. Cycling conditions were $94^{\circ} \mathrm{C}$ for $1 \mathrm{~min}, 55^{\circ} \mathrm{C}$ for $1 \mathrm{~min}$ and $72^{\circ} \mathrm{C}$ for $2 \mathrm{~min}$ for 40 cycles followed by a 5 min extension at $72^{\circ} \mathrm{C}$. Buffer, primers and dNTPs were removed by ultrafiltration in a Centricon 30 column (Amicon, Inc.). cDNAs were collected and diluted to $20 \mathrm{ng} / \mu \mathrm{l}$ in TE.

\section{RADES - PCR}

Double-stranded cDNA served as the template for arbitrary primers in the subsequent RADES-PCR fingerprinting reactions as previously described (Murphy and Pelle, 1994). PCR reactions were carried out at two template concentrations to generate reproducible fingerprints. $P C R$ reactions were carried out using a single arbitrary primer, 1501 (CGG CCG GTC A), shown previously to generate differentially expressed products late in the death process (Murphy and Welburn, 1997). PCRs contained $1 \mu \mathrm{l} 20 \mathrm{ng}$ and (2 ng) target cDNAs and the volume brought to $10 \mu \mathrm{l}$ with water/10 $\mathrm{mM}$ Tris $\mathrm{HCl}$ ( $\mathrm{pH} 8.3) / 50 \mathrm{mM} \mathrm{KCl} / 3 \mathrm{mM} \mathrm{MgCl} / 2 / 0.05 \%$ (v/v) NP40/0.05\% v/v Tween $20 / 200 \mu \mathrm{M}$ of dNTPs $/ 0.6 \mu \mathrm{M}$ primer/0.5 units of Taq (Thermus aquaticus) DNA polymerase (Promega) in a volume of $20 \mu \mathrm{l}$, and were performed on a programmable thermal cycler (MJ. Research). Cycling conditions were $94^{\circ} \mathrm{C}$ for $45 \mathrm{~s}, 40^{\circ} \mathrm{C}$ for $1 \mathrm{~min}$ and $72^{\circ} \mathrm{C}$ for $1 \mathrm{~min}$ for 40 cycles followed by an extension at $72^{\circ} \mathrm{C}$ for $5 \mathrm{~min}$. Amplification products were analyzed by electrophoresis in a $3 \%$ $(\mathrm{w} / \mathrm{v})$ MetaPhor $^{\mathrm{TM}}$ agarose gel and detected by UV illumination following staining with $\mathrm{EtdBr}$.

\section{Reamplification and cloning of RADES products}

RADES products were re-amplified using the PCR conditions described above and cloned after gel purification in pGEM-T (Promega) for sequencing. RADES products were subsequenly labelled and used to screen genomic lambda gt11 libraries of $T$. $b$. brucei.

\section{Northern analysis}

For analysis of RNA fidelity and Northern analysis using full length genes for prohibitin and TRACK the different procyclic T. $b$. rhodesiense were generated by treatment of log phase trypanosomes $\left(10^{6}\right.$ trypanosomes $/ \mathrm{ml}$ ) with $1 \mu \mathrm{g} / \mathrm{ml}$ ConA type IV (Sigma, UK) in procyclic culture media (Cunningham's supplemented with 17\% FBS) and harvested $0,4,8,24$ and $48 \mathrm{~h}$ after treatment for hybridization with prohibitin CDNA and $0,4,7,24$, and $48 \mathrm{~h}$ after treatment for hybridization with TRACK CDNA. RNA from mammalian bloodstream parasites were prepared from short stumpy and long slender purified parasites as described in Murphy and Pelle (1994). RNA gels and subsequent Northern blot analysis of these RNAs were performed as previously described (Pelle and Murphy, 1993) using full length prohibitin and TRACK DNAs. Northern blots of these RNAs were subsequently washed and hybridized with $\beta$-tubulin to confirm fidelity of the RNA and to confirm equal intensity labelling of message for this housekeeping gene over the $48 \mathrm{~h}$ period of ConA treatment and also in long slender and short stumpy bloodstream forms. 


\section{Acknowledgements}

This work is supported by the Wellcome Trust (Career Development Award to S.C.W), the Animal Health Programme of ILRI and BADC (N.B.M).

\section{References}

Ameisen JC, Idziorek T, Billaut-Mulot O, Loyens M, Tissier JP, Potentier A and Ouaissi A (1995) Apoptosis in a unicellular eukaryote (Trypanosoma cruzi): implications for the evolutionary origin and role of programmed cell death in the control of cell proliferation, differentiation and survival. Cell Death Diff. 2: 285300

Amiesen JC (1996) The origin of programmed cell death. Science 272: 1278-1279

Asamoto M and Cohen SM (1994) Prohibitin gene is overexpressed but not mutated in rat bladder carcinomas and cell lines. Cancer Lett. 83: 201-207

Choongkittaworn NM, Kim KH, Danner, DB and Griswold MD (1993) Expression of prohibitin in rat seminiferous epithelium. Biol Reprod. 49: 300-310

Coates PJ, Jamieson DJ, Smart K, Prescott AR and Hall PA (1997) The prohibitin family of mitochondrial proteins regulate replicative lifespan. Current Biol. 7: $607-610$

Cornillon S, Foa C, Davoust J, Buonavista N, Gross JD and Golstein P (1994) Programmed cell death in Dictyostelium. J. Cell Sci. 107: 2691-2704

Diaz-Meco MT, Municio MM, Frutos S, Sanchez P, Lozano J, Sanz L and Moscat J (1996) The product of par-4, a gene induced during apoptosis, interacts selectively with the atypical isoforms of protein kinase C. Cell 86: 777-786

Eveleth DD and Marsh JL(1986) Sequence and expression of the Cc gene, a member of the dopa decarboxylase gene cluster of Drosophila: possible transcriptional regulation. Nucleic Acids Res. 14:6169-6183

Frankin DS and Jazwinski SM (1993) A yeast homolog of the rat prohibitin gene is differentially expressed and determines longevity in Saccharomyces cervisiae. J. Cell. Biol. 17D: 159 (abstract).

Huang B, Eberstadt M, Olejniczak ET, Meadows RP and Fesik W (1996) NMR structure and mutagenesis of the Fas (APO-1/CD95) death domain. Nature 348 : 638-641

Ikonen E, Fiedler K, Parton RG and Simons K (1995) Prohibitin, an antiproliferative protein is localised to mitochondria. FEBS Lett. 358: 273-277

Ink B, Zornig M, Baum B, Hajibagheri N, James C, Chittenden T and Evan G (1997) Human Bak induces cell death in Schizosaccharomyces pombe with morphological changes similar to those with apoptosis in mammalian cells. Mol. Cell Biol. 17: 2468-2474

Jazwinski SM (1996) Longevity, genes and ageing. Science 273: 54-59

Lavin MF, Watters D and Song Q (1996) Role of protein kinase activity in apoptosis. Experimentia 52: $979-994$

Liu X-T, Stewart CA, King RL, Danner DA, Dell'Orco RT and McClung JK (1994) Prohibitin expression during cellular senescence of human diploid fibroblasts Biochem. Biophys. Res. Commun. 201: 409-414
Moiera MEC, Del Portillo HA, Milder R, Balanco JMF and Barcinski MA (1996) Heat shock induction of apoptosis in promastigotes of the unicellular organism Leishmania (Leishmania) amazonensis. J. Cell. Physiol. 167: 305-313

Mougneau E, Altare F, Wakil AE, Zheng S, Coppola T, Wang ZE, Waldmann R, Locksley RM and Glaichenhaus N (1995) Expression cloning of a protective Leishmania antigen. Science 268: 563-566

Mochly-Rosen D, Smith BL, Chen CH, Disatnik MH and Ron D (1995) Interaction of protein kinase $C$ with $R A C K 1$, a receptor for activated protein kinase $C$ : a role in beta protein kinase $C$ mediated signal transduction. Biochem Soc Trans 23: $596-600$

Murphy NB and Pelle R (1994) The use of arbitrary primers and the RADES method for the rapid identification of developmentally regulated genes in trypanosomes. Gene 141: 53-61

Murphy NB and Welburn SC (1997) Programmed cell death in T.b.rhodesiense is associated with up-regulation of mRNAs. Cell Death Differ. 4: 365-370

Nuell MJ, Stewart DA, Walker L, Freidman V, Wood CM, Owens GA, Smith JR, Schneider EL, Delq Orco R and Lumpkin CK (1991) Prohibitin, an evolutionarily conserved intracellular protein that blocks DNA synthesis in normal human fibroblasts and HeLa cells. Mol Cell Biol. 11: 1372-1381

Pelle R and Murphy NB (1993) Northern hybridization: rapid and simple electrophoretic conditions. Nucleic Acids Res. 21:2783-2784

Sato T, Saito H, Swensen J, Olifant A, Wood C, Danner D, Sakamoto T, Takita K, Kasumi F and Miki Y (1992) The human prohibitin gene located on chromosome 17q21 is mutated in sporadic breast cancer. Cancer Res. 52: 2643-2646

Sells SF, Wood DP, Joshi-Barve SS, Muthukumar S, Jacob RJ, Crist S, Humphreys SA and Rangnekar VM (1994) Cell Growth Diff. 5: 457-466

Sells SF, Han SS, Muthukkumar S, Maddiwar N, Johnstone R, Boghaert E, Gillis D, Liu G, Nair P, Monnig S, Collini P, Mattson MP, Sukhatme VP, Zimmer SG, Wood DP, McRoberts JW, Shi Y and Rangneker VM (1997) Expression and function of the leucine zipper protein Par-4 in apoptosis. Mol Cell Biol. 17: 3823-3832

Snedden WA and Fromm H (1997) Characterisation of the plant homologue of prohibitin, a gene associated with antiproliferative activity in mammalian cells. Plant Mol Biol. 33: 753-756

Tao W, Kurschner C and Morgan Jl (1997) Modulation of cell death in yeast by the Bcl2 family of proteins. J. Biol. Chem. 272: 15547-15552

Terashima M, Kim KM, Adachi T, Nielson PJ, Reth M, Kohler G and Lamers C (1994) The IgM antigen receptor of $b$ lymphocytes is associated with prohibitin and $a$ prohibitin-related protein. EMBO J. 13: 3782-3792

Vickerman K (1985) Antigenic variation in trypanosomes. Brit. Med. Bull. 41: $105-$ 114

Welburn SC, Dale C, Ellis D, Beecroft R and Pearson TW (1996) Apoptosis in procyclic T. b. rhodesiense in vitro. Cell Death Diff. 3: 229-236

Welburn SC, Barcinski MA and Williams GT (1997) Programmed cell death in trypanosomatids. Parasitol. Today 13: 22-25 